\title{
COST ANALYSIS OF DIFFERENT OPERATION STRATEGIES FOR FALLING PARTICLE RECEIVERS
}

\author{
Birgit Gobereit \\ German Aerospace Center (DLR) \\ Pfaffenwaldring 38-40, 70569 Stuttgart, Germany \\ Reiner Buck \\ German Aerospace Center (DLR) \\ Pfaffenwaldring 38-40, 70569 Stuttgart, Germany
}

\author{
Lars Amsbeck \\ German Aerospace Center (DLR) \\ Pfaffenwaldring 38-40, 70569 Stuttgart, Germany \\ Csaba Singer \\ German Aerospace Center (DLR) \\ Pfaffenwaldring 38-40, 70569 Stuttgart, Germany
}

\begin{abstract}
The potential for highly efficient and cost competitive solar energy collection at high temperatures drives the actual research and development activities for particle tower systems. One promising concept for particle receivers is the falling particle receiver. This paper is related to a particle receiver, in which falling ceramic particles form a particle curtain, which absorbs the concentrated solar radiation. Complex operation strategies will result in higher receiver costs, for both investment and operation. The objective of this paper is to assess the influence of the simultaneous variation of receiver costs and efficiency characteristics on levelized cost of heat (LCOH) and on levelized cost of electricity (LCOE).

Applying cost assumptions for the particle receiver and the particle transport system, the LCOE are estimated and compared for each considered concept. The power level of the compared concepts is $125 \mathrm{MW}_{\mathrm{el}}$ output at design point. The sensitivity of the results on the specific cost assumptions is analyzed. No detailed evaluation is done for the thermal storage, but comparable storage utilization and costs are assumed for all cases.
\end{abstract}

Keywords:

Concentrated Solar Power (CSP), Solid Particle Receiver (SPR), Falling Particle Receiver, Recirculation

\section{INTRODUCTION}

For solar tower systems, solid particle receivers (SPR) are considered as a promising concept to convert the solar radiation into heat. Ongoing research activities are based on the potential of the technology that results from advantages over state-of-the art technologies. Basically, SPR absorb the solar radiation directly in moving solid particles. The main advantages of SPR are

- Direct absorption by the particles, reducing the need for expensive high temperature materials.

- $\quad$ High operation temperatures possible (up to $1000^{\circ} \mathrm{C}$ ).

- Adequate ceramic particles are commercially available.

- Particles can be used as absorber and storage material.

- High temperature spread and heat capacity allows high storage densities.

- Pressureless receiver design with open aperture possible.

Falling particle receivers (FPR) are a special kind of SPR, in which particles fall down grafity driven. In this paper only FPR are considered. Investigations regarding the FPR started in the 1980s at Sandia National Laboratories (1, 2). A small prototype was tested on-sun on the solar tower in Albuquerque in the early $21^{\text {st }}$ century (8). Beyond the demonstration of the feasibility of a particle receiver, the experimental data was used for model validation $(4,5)$. Meier presented numerical studies on the particle flow behavior for a falling particle receiver/reactor for a cement production process (6). These investigations were related to a flat shaped particle curtain that was formed by particles, which fall downwards in a cavity. The apertures of the proposed cavities were located sidewise.

Another field of work is a cavity receiver, which has a downwards-facing aperture: the face-down receiver concept. The particles fall down in the cavity, located near to the inner 
receiver walls. At the bottom the particles are collected by a collection ring.

So far, the face-down concept has only been evaluated theoretically for cubical and cylindrical cavities $(7,8,9)$.

The advantage of this receiver concept is a reduction of convection losses due to the downwards-facing aperture, and the closed cavity, in which the hot air forms a stagnation zone (hot air in the upper part of the receiver, colder air in the lower part). This was quantified by using a CFD-model (8).

A specific problem of FPR occurs in part-load situations. When the incident solar power is reduced, the total particle mass flow must be reduced accordingly to maintain the desired particle outlet temperature. However, the reduced particle mass flow means an optically less dense particle film, resulting in lower overall absorption and higher reflection losses in the cavity.

In previous studies different operation strategies have been assessed to increase the receiver efficiency. To yield high part load efficiency, recirculation of particles was proposed (7). The two different operation strategies (with or without recirculation) are schematically shown in Figure 1.

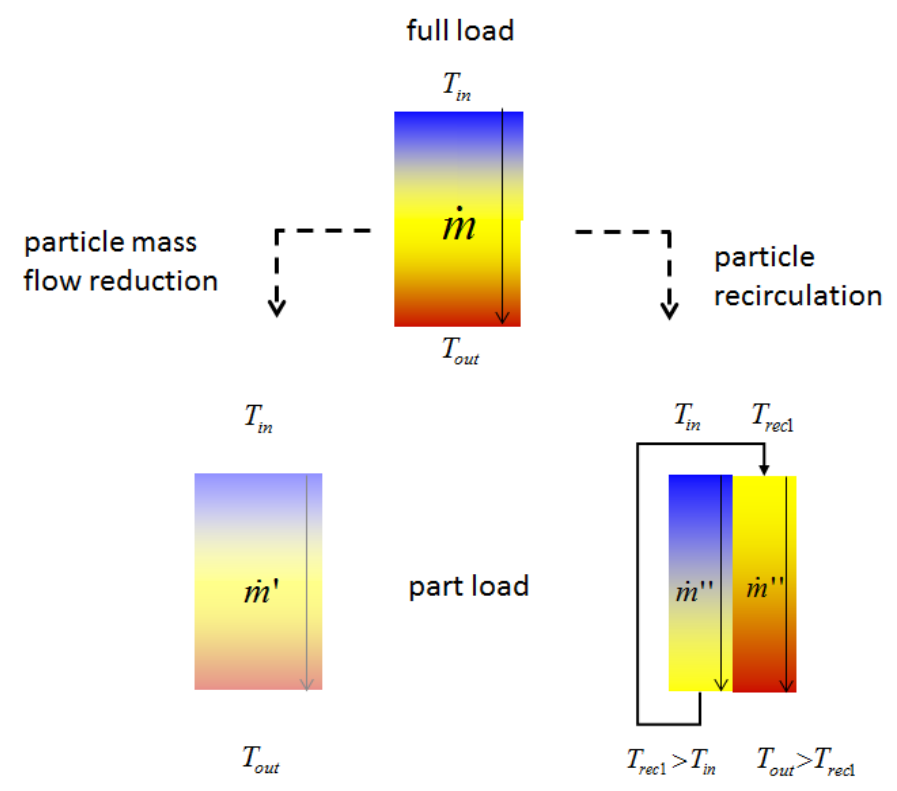

Figure 1: Top: operation under design point conditions (full load); bottom: part load operation strategies to yield same particle outlet temperature; left: operation without recirculation, mass flow reduction, low specific mass flow in cavity; right: operation with one recirculation, higher specific particle mass flow in cavity

In recirculation mode, the particle curtain is divided into several parallel sections. The particles are falling through each section, i. e. the drop more than once through the cavity. After each drop the particles are collected and circulated back to the inlet of the next receiver section. After the last section, the particles are exiting the receiver. Thus, the particles are heated step by step to the receiver outlet temperature at the end of the last section. Since the particle mass flow in each section equals the total receiver mass flow, but at a significantly smaller curtain width, the particle curtain stays denser and the receiver losses due to reflection and emission can be reduced.

\section{MODELING}

For assessment of LCOH and LCOE system analysis were performed for operation with and without recirculation. The main focus of the system analysis was to determine the economic potential of the recirculation strategy.

The economic studies were based on common used tools and assumptions, which are described briefly in the following section "System Analysis". Essential input data for the economic assessment are cost data, which are discussed in the section "Model Parameters" as well as the receiver efficiency characteristic curves. A summary of the methodology and assumptions for computation of receiver efficiency is given in section "Particle Receiver Modeling".

\section{System Analysis}

The assessment is based on a modified and extended methodology of the European Concentrated Solar Thermal Roadmap (ECOSTAR) study and enables the prediction of the annual performance and the LCOE. The annual analysis uses as input an optimized heliostat field with optimized tower height, a receiver model with given aperture size considering its obtained efficiency characteristics (see next section), a piping model, using empirical correlations for the HTM flow in piping, a simplified storage model and $100 \%$ solar only operation strategy and a simplified model of the power block considering also the steam generator. The detailed model explanation of the used system analysis dataflow and sensitivity analysis is given in previously published literature $(11,14)$. The overall assessment dataflow of the coupled tools is described in (12) and sketched in Fig. 2. In this context Fig. 2 depicts exemplary the connections of the relevant components and assumptions. For the heliostat field layout HFLCAL (10) and for the subsequent annual performance analysis and cost calculation the ECOSTAR methodology, which enables an hourly based annual performance and cost calculation, was used. The power block was modeled with the software Ebsilon. To be able to analyze a high number of system variations a master tool was programmed to automatically control the field layout, optimization, data transfer between the tools, annual analysis, system optimization and reporting of results. The advantages of this approach lie mainly in the simplified handling of the calculation process, reduced error rate due to user input errors and most of all net processing time. 


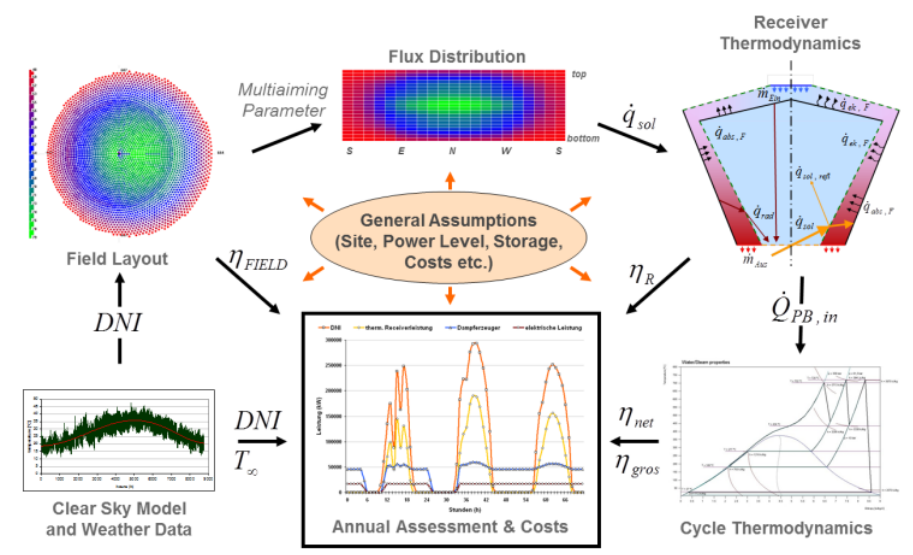

Figure 2: Sketch of the Annual Analysis Dataflow

\section{Particle Receiver Modeling}

Receiver efficiency characteristics were determined with a coupled CFD and ray tracing simulation for operation with and without recirculation and different solar loads. The receiver output power in design point was $355 \mathrm{MW}_{\text {th }}$. The receiver inlet temperature was set to $300^{\circ} \mathrm{C}$ and the desired particle outlet temperature was $800^{\circ} \mathrm{C}$. In the following the modeling approaches are described briefly. Further information can be found in literature (9).

The proposed concept for the particle receiver was a falling particle curtain, which is falling down parallel to the inner wall of a cylindrical cavity. The particles collected at the bottom in a collection ring, which borders the open down-facing aperture. This so-called face-down cavity was simulated with numerical fluid dynamic simulation with the CFD-code (CFX). With a two-phase flow model the continuous fluid and discrete particles were simulated (Euler-Lagrange approach). Particle volume fraction distribution can be extracted from the CFD simulation result and used as input data for a ray tracing software, based on the SPRAY code. The principle for these subsequent ray tracing simulation is shown in Figure 3.

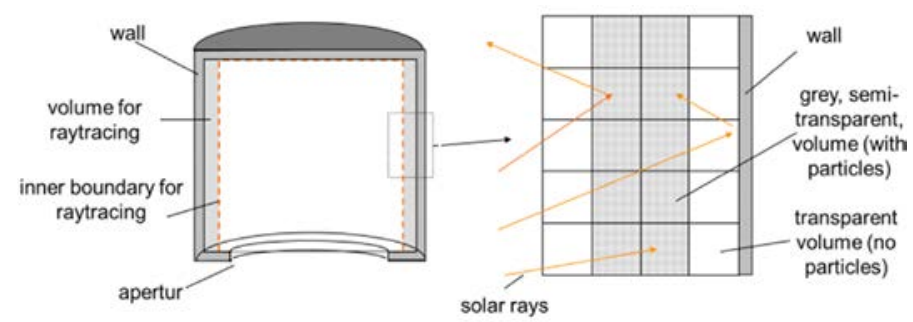

Figure 3: Principle of solar ray tracing for falling particle receiver modeling (left: half section of cylindrical face down cavity, right: of interaction between rays and volumes/faces).
As indicated in the schematic view in figure 3 the impinging rays can either

- be reflected by a particle loaded volume,

- be absorbed by a particle loaded volume,

- be transmitted through a particle loaded volume,

- be reflected by a wall,

- be absorbed by a wall, or

- leave the cavity through the aperture.

These quantities are determined statistically, depending on local particle volume fraction, properties of particles, and walls. So, with ray tracing simulation absorption of directional radiation from heliostat field in the particle loaded volumes and on receiver walls can be determined. Rays that leave the aperture are summed up to determine total reflection losses.The quantities for the absorbed radiation are used as input data for a sequential CFD simulation.

This CFD simulation includes:

- movement of the air (numerical fluid dynamics),

- movement of particles (discrete approach),

- momentum coupling between air and particles (Schiller-Naumann correlation),

- thermal radiation (diffuse, discrete ordinate model),

- convective heat transfer between wall and air (thermal wall function),

- convective heat transfer between air and particles (Ranz-Marshall correlation).

Particle mass flow rates were adapted to yield a temperature rise from $300^{\circ} \mathrm{C}$ to $800^{\circ} \mathrm{C}$. Heat losses during recirculation were considered negligible. Windless conditions were considered for the presented cases.

Heating of the particles by the solar radiation leads also to heating of the air in the cavity. As a consequence, air properties and flow field in the cavity changes, which leads to modification of particle movement and volume fraction distribution. Thus, intermediate solutions were iterated between CFD and ray tracing until convergence was reached.

From a converged solution, receiver efficiency for one operation point can be determined. Receiver efficiency is defined as ratio of thermal output power to solar input power

$$
\eta_{\text {receiver }}=\frac{\text { thermal output power from receiver }}{\text { solar input power into receiver }}
$$

Receiver efficiency was determined in different load points and for operation with three subsequent recirculation steps and without recirculation to yield the efficiency characteristic curves. Computed receiver efficiencies in different load points were fitted with the following curves, to determine model parameters for yearly simulations. Figure 4 shows two 
efficiency curves as function of input power relative to design point power $($ design point $=100 \%)$.

Main difference in efficiency is due to reduction of reflection losses. In design point reflection losses reduces from 9.8 to $2.2 \%$. Because of higher transparency of the particle curtain at part load, the difference between the two cases increases, for example in excess of $10 \%$-point at $50 \%$ part load.

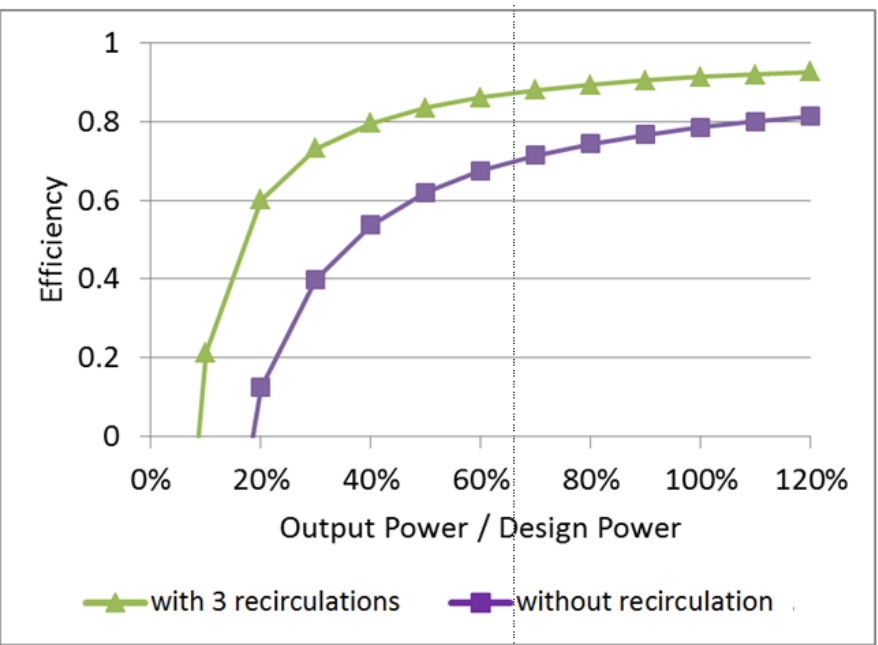

Figure 4: Receiver efficiency as function of input power relative to design point power (design point $=100 \%$ ); for operation without recirculation and with three recirculations.

\section{MODEL PARAMETERS}

\section{Model Parameters}

The reference concept for the comparison here refers to a FPR without recirculation assuming a power level of $125 \mathrm{MW}_{\mathrm{el}}$. The site of the comparison is chosen to be Barstow $\left(34.85^{\circ} \mathrm{N} /\right.$ $116.8^{\circ} \mathrm{E} / 600 \mathrm{~m}$ above sea level $/ \mathrm{DNI}$ at DP $=901 \mathrm{~W} / \mathrm{m}^{2}$ ) while the design point (DP) is chosen to be March 21, 12:00 solar time. The main specifications of the reference concept are given in Table 1 . For the receiver model, the particles were assumed to be gray with an absorptivity of 0.93 and the same value for emissivity. For the walls different values for solar absorptivity (0.25) and thermal emissivity (0.8) was assumed. These optical properties are in accordance with previous publications (2-5).

\section{Cost Assumptions}

The underlying cost assumptions for the annual analysis and assessment of LCOE are discussed below.

\section{a) General Costs}

General costs dataset is comparable to previous assessments $(11,12)$, where todays molten salt state-of-the-art technology was analyzed. Similarity is only considered for general costs dataset like heliostats or financing assumptions, which should be comparable. Differences to state of the art have been taken into account with a first best-guess for cost
Table 1: Main specification of the reference FPR concept

\begin{tabular}{ll}
\hline Solar Field & $360^{\circ}$ (surrounding field) \\
\hline Type & $121 \mathrm{~m}^{2}$ \\
Reflective area of one heliostat & $89.34 \%$ \\
Effective reflectivity & $3.664 \mathrm{mrad}$ \\
Beam error & 2.5 \\
Solar multiple & Falling Particle Receiver \\
\hline Receiver & FPR in face-down cavity \\
\hline Type & sintered bauxite particles \\
Heat transfer medium (HTM) & $697 \mu \mathrm{m}$ diameter \\
Particle diameter & $300^{\circ} \mathrm{C}$ \\
Particle inlet temperature & $800^{\circ} \mathrm{C}$ \\
Particle outlet temperature & 0.93 \\
Particle absorptivity (solar) & 0.93 \\
Particle emissivity (thermal) & 0.25 \\
Wall absorptivity(solar) & 0.8 \\
Wall emissivity (thermal) & \\
\hline Heat Transport System & Batch-transport in insulated containers \\
\hline Type & Not necessary \\
Heat tracing & 2 -tank direct storage \\
\hline Thermal Storage System & \\
\hline Power block & $550^{\circ} \mathrm{C}$ \\
\hline Type & \\
Life Steam Pressure & Labcritical steam turbine \\
Life Steam Temperature & \\
\hline & \\
\hline
\end{tabular}

assumptions. The general cost assumptions are listed in Table 2 and were discussed in the previous study related to increased receiver temperatures (12). Annual assessment also considers cost assumptions related to the labor costs per employee, number of persons for development, operation and the field maintenance, specific water cost, O\&M Equipment costs percentage of investment annual insurance cost and service including equipment (for staff, water, etc.).

\section{b) Particle Cycle}

With the particle temperature of $800^{\circ} \mathrm{C}$ after the receiver and $300^{\circ} \mathrm{C}$ after the steam generator, a particle amount of $6.1 \mathrm{~kg}$ is needed per kWh of storage capacity. At particle costs of $1.2 \$ / \mathrm{kg}$ this corresponds to $7.3 \$ / \mathrm{kWh}$ for the particle inventory of the storage. A commercial offer for a smaller tank structure using high temperature steel as the tank shell and an outer insulation was extrapolated resulting in total specific storage costs of $18 \$ / \mathrm{kWh}_{\mathrm{th}}$. This number is a bit higher than the previously stated $\$ 5-\$ 6 / \mathrm{kWh}_{\mathrm{th}}$ for a particle storage system with very low cost particles and ceramic construction materials (13). 
As actually no reliable cost data for falling particle receivers is available, a sensitivity study regarding the costs is presented, to show the influence of receiver costs and performance of the entire plant on the LCOE.

Receiver costs which include the particle transport system system were varied from 12 to $204 \$ / \mathrm{kW}_{\text {th }}$ as especially for the transport system cost numbers are still quite uncertain. Cost for the recirculation system (insulated containers and lift system) are not considered. Therefore, the difference between both case can be considered as economic limit for the additional costs of recirculation. Outer receiver wall structure is expected in the range of $12 \$ / \mathrm{kW}_{\text {th }}$ corresponding to the lower price range. Batch transport systems in the mining industry (skip hoists) with comparable transport capacities per height result in receiver costs of $\sim 60 \$ / \mathrm{kW}_{\text {th }}$. An upper limit of $204 \$ / \mathrm{kW}_{\text {th }}$ is chosen to reflect the handling of hot materials (insulated skip and hot input/output system) and the recirculation system.

\section{c) Balance of Plant}

The power block input data was provided by a turbine manufacturer and is confidential. Therefore only the relative economic comparison of the concept variants is carried out. Furthermore, to consider cost insecurities related to a steam generator that uses hot particles as the heat source the steam generator's cost are varied. Cost for power block without steam generator were assumed to be $625 \$ / \mathrm{kW}_{\mathrm{el}}$. This estimation is based on values known from literature $(15,16)$.

Steam generator costs were varied between 240 and $720 \$ / \mathrm{kW}_{\mathrm{el}}$. This wide cost assumption range is chosen to cover high uncertainties related to a steam generator system that is driven by hot particles.

\section{RESULTS}

In Figure 5 the calculated $\mathrm{LCOH}$ related to both receiver concept options is depicted. The values are normalized to the case with recirculation and mean cost assumption. For the considered case, $\mathrm{LCOH}$ is $11-15 \%$ higher for the case with recirculation than for the case without, respectively 10 to $12 \%$ points difference referred to normalized LCOH. With the present cost assumptions, up to $0.03 \$ / \mathrm{kWh}_{\mathrm{th}}$ can be saved, if for the FPR three recirculation stages are considered and if for both receiver concepts the same power specific costs are assumed. A FPR with three recirculation stages is allowed to cost up to $60 \$ / \mathrm{kW}_{\text {th }}$ more to reach the same $\mathrm{LCOH}$ like without recirculation stages.
Table 2: Cost assumptions FPR system

\begin{tabular}{ll}
\hline $\begin{array}{l}\text { a) General costs } \\
\text { Components/ other costs }\end{array}$ & Costs* \\
\hline Heliostats (incl. installation) & $168 \$ / \mathrm{m} 2$ \\
Tower & $300000 \$+17.72 \$ \cdot$ HT2.39 \\
Labor costs per employee & $48000 € /$ year \\
number of persons (w/o field maintenance) & 30 \\
spec. number of persons for maintenance & 0.03 per m² heliostat \\
O\&M Equipment costs (\% of investment) & $2 \%$ per year \\
annual insurance cost (\% of EPC) & $0.3 \%$ \\
service equipment (\% of EPC) & $2.5 \%$ \\
indirect costs (\% of EPC) & $30 \%$ \\
Financing (dept interest rate) & 0.075
\end{tabular}

b) Particle Cycle

$\begin{array}{ll}\text { Components } & \text { Costs }^{1}\end{array}$

Receiver (parameter variation) 12 to 204 \$/kWth

Thermal Storage $\quad 15 € / \mathrm{kWh}$

c) Balance of plant

Components Costs ${ }^{1}$

Power Block (without Stem Generator) 625 \$/kWel

Steam Generator (parameter variation)

240 / 480 / 720 \$/kWel

* cost assessment based on data in $€$, assumed exchange rate for cost data $1 €=\$ 1.2$

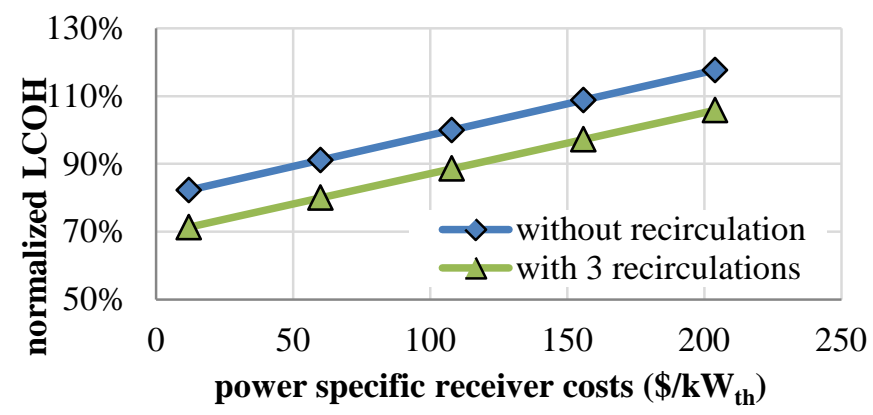

Figure 5: Normalized LCOH using an FPR with or without recirculation. 
In Figure 6 the obtained normalized LCOE of both receiver concept options is shown. As additional parameter the specific costs of the steam generator operated by hot bauxite particles are varied between 240 and $720 \$ / \mathrm{kW}_{\mathrm{el}}$.

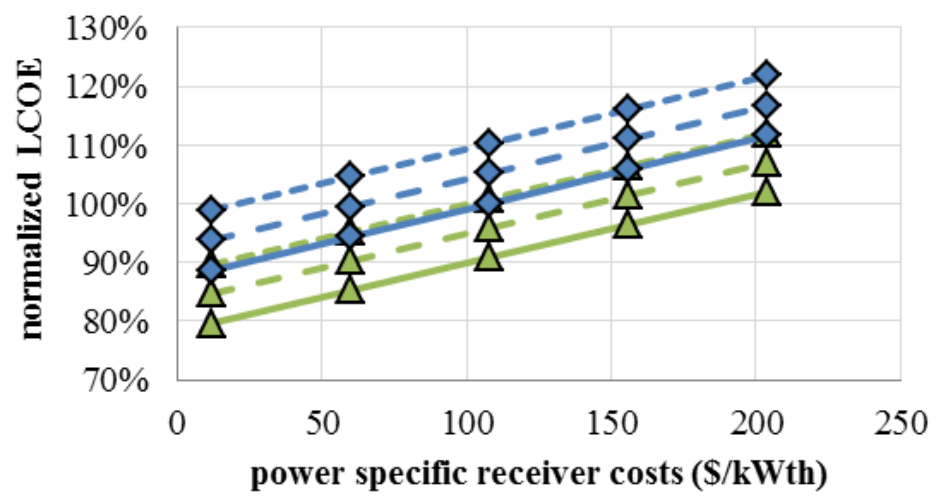

$$
\begin{aligned}
& \triangle \text { with } 3 \text { recirculations, } \mathrm{SG}=240 \$ / \mathrm{kWel} \\
& -\triangle \text { with } 3 \text { recirculations, } \mathrm{SG}=480 \$ / \mathrm{kWel} \\
& -\triangle-\text { with } 3 \text { recirculations, } \mathrm{SG}=720 \$ / \mathrm{kWel} \\
& \checkmark \text { without recirculation, } \mathrm{SG}=240 \$ / \mathrm{kWel} \\
& -\prec \text { without recirculation, } \mathrm{SG}=480 \$ / \mathrm{kWel} \\
& -\prec-\text { without recirculation, } \mathrm{SG}=720 \$ / \mathrm{kWel}
\end{aligned}
$$

Figure 6: Normalized LCOE using an FPR with or without recirculation.

Up to $0.012 \$ / \mathrm{kWh}_{\mathrm{el}}$ can be saved, if the FPR applies the considered recirculation stages independent from the costs of the steam generator. Furthermore it can be stated that for the assessed options a steam generator that costs $240 \$ / \mathrm{kW}_{\text {el }}$ more leads to $0.006 \$ / \mathrm{kWh}_{\mathrm{el}}$ higher LCOE. The optimal storage capacities of all assessed variants yield to $12 \mathrm{~h}$ full load operation of the power plant. The approach of storage capacity optimization is carried out in two steps. First with a given range of solar multiples (SM) various system layouts take place. Then a parameter variation of the storage capacity is carried out. The storage capacity that leads to the lowest LCOE is taken as the optimal storage capacity corresponding to the assumed SM. The range of calculated annual component efficiencies lie in a ranges listed in Table 3.

Table 3: Ranges of calculated annual component efficiencies

\begin{tabular}{ll}
\hline Component & Costs \\
\hline Solar Field & $52.6 \%-56.3 \%$ \\
Receiver & $75.6 \%-82.9 \%$ \\
Power Block (gross) & $45.4 \%$ \\
Power Block (net) & $42.6 \%$ \\
Whole Power Plant (net) & $17 \%-19.7 \%$ \\
\hline
\end{tabular}

\section{CONCLUSION}

Two different operating strategies for solar falling particle receivers were investigated and compared: without recirculation and with three-fold recirculation. Recirculation results in an optically denser particle film that reduces solar and thermal losses, thus achieving higher receiver efficiency. This is especially valid for part-load operation conditions.

On the other hand, recirculation means higher technical efforts and more equipment to transport the heated particles several times back to the particle inlet. Consequently, a receiver with recirculation will be more expensive. As the additional cost for recirculation is not known yet, a cost sensitivity study was made. In this study, the receiver cost as well as the cost for the particle steam generator was varied.

With optimized plant parameters and for specific receiver costs of 12 to $204 \$ / \mathrm{kW}^{1}$, without recirculation the receiver efficiency decreases and with the same costs assumptions the $\mathrm{LCOH}$ increases 11 to $15 \%$ referred to the operation with recirculation. This gap is the "economic potential", or in other words: higher costs for a receiver with a recirculation system should not overcompensate this efficiency advantage or the simpler receiver design has to reach a significant cost reduction to be competitive. To overcompensate the drawbacks in the efficiency characteristics the specific investment costs for the falling particle receiver have to be lower than $34 \$ / \mathrm{kW}_{\text {th }}$ for this case.

Considering LCOE, a receiver with recirculation can be about $65 \$ / \mathrm{kW}_{\text {th }}$ more expensive to achieve the same LCOE than a receiver without recirculation. Whether the additional equipment for recirculation can be built for this cost difference, is not known yet.

The variation of the particle steam generator cost shows similar trends in all configurations. An increase of steam generator cost by $480 \$ / \mathrm{kW}_{\mathrm{el}}$ results in an increase of the LCOE by about $0.012 \$ / \mathrm{kW}_{\mathrm{el}}$.

\section{NOMENCLATURE}

DNI direct normal insolation

DP design point

HTM heat transfer medium

LCOE levelized cost of electricity

LCOH levelized cost of heat

FPR falling particle receiver

SPR solid particle receiver

\section{ACKNOWLEDGMENTS}

The authors want to thank the steam turbine manufacturer for providing the details on the performance and the cost of the appropriate steam turbine.

\footnotetext{
${ }^{1}$ Parameter variation over wide range around Sunshot goal $125 \$ / \mathrm{kWth}$
} 


\section{REFERENCES}

(1) Martin, J., and Vitko, J., 1982, “ASCUAS: A Solar Central Receiver Utilizing a Thermal Carrier,” SAND82-8203, Sandia National Laboratories, Albuquerque, NM.

(2) Hruby, J. M., 1986, “A Technical Feasibility Study of a Solid Particle Solar Central Receiver for High Temperature Applications,” SAND86-8211, Sandia National Laboratories, Albuquerque, NM.

(3) Siegel, N., Kolb, G., 2008,” Design and On-Sun Testing of a Solid Particle Receiver Prototype”, Proc. of Energy Sustainability Conference ES2008.

(4) Ho, C., Khalsa S., Siegel, N., 2009, "Modeling On-Sun Tests of a Prototype Solid Particle Receiver for Concentrating Solar Power Processes and Storage”, Proc. of Energy Sustainability Conference ES 2009.

(5) Ho, C., Röger, M., Khalsa S., Amsbeck, L., Buck, R., Siegel, N., Kolb, G., 2009, "Experimental Validation of Different Modeling Approaches for Solid Particle Receivers”, SolarPACES 2009, Berlin, Deutschland.

(6) Meier, A., 1999,”A predictive CFD model for a falling particle receiver/reactor exposed to concentrated sunlight”, Chemical Engineering Science 54, pp. 2899 - 2905.

(7) Röger, M., Amsbeck, L., Gobereit, B., Buck, R.: “FaceDown Solid Particle Receiver Using Recirculation“, 2011, J. Sol. Energy Engineering.

(8) Khalsa, S., Christian, J., Kolb, G., Röger, M., Amsbeck, L.; Ho, C., Siegel, N., Moya, A., 2011, “CFD Simulation and Performance Analysis of Alternative Designs for HighTemperature Solid Particle Receivers”, Proc. of Int. Conf. on Energy Sustainability, ES 2011, Washington.

(9) Gobereit, Birgit und Amsbeck, Lars und Buck, Reiner und Müller-Steinhagen, Hans und Pitz-Paal, Robert, 2012, “Assessment of a Falling Solid Particle Receiver with Numerical Simulation”. SolarPACES 2012, Morocco. (10) Schwarzbözl, P., Pitz-Paal, R., and Schmitz, M., 2009, "Visual HFLCAL - A Software Tool for Layout and Optimisation of Heliostat Fields," Proceedings of 15th International SolarPACES Symposium, Berlin, September 15-18.

(11) Singer, Cs. et al.: Economic Potential of Innovative Receiver Concepts with Different Solar Field Configurations for Supercritical Steam Cycles. Journal of Solar Energy Engineering, 136, 021009-1; 2013.

(12) Singer, Cs. et al.: Assessment of Improved Molten Salt Solar Tower Plants. Proc. SolarPACES, 17.-20. Sept., Las Vegas, USA, 2013.

(13) Maa, Z., Mehos, M., Glatzmaier, G. and Sakadjianb, B.B., "Development of a Concentrating Solar Power System Using Fluidized-Bed Technology for Thermal Energy Conversion and Solid Particles for Thermal Energy Storage”, International Conference on Concentrating Solar Power and Chemical Energy Systems, SolarPACES 2014, Beijing/China. (14) Csaba Singer, Reiner Buck, Robert Pitz-Paal, Hans MüllerSteinhagen: "Assessment of Solar Power Tower Driven Ultrasupercritical Steam Cycles Applying Tubular Central Receivers With Varied Heat Transfer Media", Proceedings. Energy Sustainability 2009, 19.-23. July 2009, San Francisco.
(15) Singer, Csaba : Solarturmreceiver für überkritische Dampfprozesse und ihre technische und ökonomische Bewertung, Dissertation, Universität Stuttgart, 2013. (16) Kolb G.J., “An Evaluation of Possible Next-Generation High-Temperature Molten-Salt Power Towers.” Sandia National Laboratories, SAND2011-9320, USA; 2011. 